УДК 630*524.634: 630*561.26: 519.876

\title{
СТРУКТУРНО-ФУНКЦИОНАЛЬНЫЕ ПАРАМЕТРЫ ДЕНДРОРЯДОВ РАЗНОВОЗРАСТНОГО СОСНЯКА СИБИРИ ПО КРИВЫМ ВЫСОТ
}

\author{
(C) 2015
}

П.М. Мазуркин, доктор технических наук, профессор,

заведующий кафедрой природообустройства,

академик РАЕ и РАЕН, член Европейской Академии Естествознания

ФГБОУ «Поволжский государственный технологический университет», Йошкар-Ола (Россия), kaf_po@mail.ru

Введение. Статистическая фитоценология [7-9]полагает моделирование бинарных отношений [2] между измеренными показателями модельных деревьев на пробной площади, в частности, сосняка [1] по данным проф. П.М. Верхунова. По 24 измеренным параметрам 203 у модельных сосен и 16 сухостоя возможны $24^{2}=576$ закономерностей, из которых 24 - ранговые распределения.

Влияние толщины ствола в лесной таксации считается основным [6]. Дополнительно для кривых высот учитывается высота ствола модельной сосны.

Цель статьи - в продолжение [1] показать методику рангового распределения толщины и высоты ствола у элементов древостоя в виде дендрометрических рядов (дендрорядов) на примере кривых высот ангарских сосен.

Исходные данные. По таблице 1 для кривых высот необходимы ранговые распределения дендрорядов по 11 показателям, включая численность. Каждый показатель имеет пять различий. Функциональная на момент рубки деревьев ситуация может быть изучена по $24 \times 5=120$ ранговым распределениям.

Таблица 1

Структурные параметры дендрорядов сосняка на пробной площади по кривым высот

\begin{tabular}{|c|c|c|c|c|c|c|c|c|c|c|c|c|}
\hline Ранг & Дендрометрический & $N$ & \multicolumn{4}{|c|}{ Параметры толщины, см } & \multicolumn{5}{|c|}{ Параметры высоты, м } \\
\cline { 5 - 13 }$p$ & ряд сосен & шт. & $D_{\min }$ & $D_{\max }$ & $\Delta D$ & $\bar{D}$ & $D^{*}$ & $H_{\min }$ & $H_{\max }$ & $\Delta H$ & $\bar{H}$ & $H^{*}$ \\
\hline 0 & Сверхлидеры & 6 & 25.8 & 66.2 & 40.4 & 42.97 & 166 & 27.4 & 32.5 & 5.1 & 29.62 & 38.1 \\
\hline 1 & Сильнейшие & 4 & 22.2 & 52.6 & 30.4 & 34.25 & 67 & 23.3 & 30.5 & 7.2 & 26.75 & 31.0 \\
\hline 2 & очень сильные & 4 & 25.4 & 56.0 & 30.6 & 37.10 & 68 & 24.2 & 30.0 & 5.8 & 26.88 & 30.3 \\
\hline 3 & Сильные & 6 & 19.8 & 43.6 & 23.8 & 30.00 & 82 & 20.3 & 28.3 & 8.0 & 24.23 & 31.3 \\
\hline 4 & слабонапряженные & 9 & 10.4 & 71.4 & 61.0 & 28.67 & 62 & 12.1 & 29.0 & 16.9 & 20.50 & 29.1 \\
\hline 5 & малонапряженные & 16 & 12.2 & 68.2 & 56.0 & 37.50 & 55 & 10.5 & 28.7 & 18.2 & 22.21 & 28.4 \\
\hline 6 & Напряженные & 9 & 23.4 & 68.6 & 45.2 & 39.89 & 62 & 22.0 & 27.8 & 5.8 & 25.28 & 27.8 \\
\hline 7 & сильнонапряженные & 16 & 19.8 & 68.2 & 48.4 & 37.97 & 66 & 19.5 & 27.6 & 8.1 & 24.74 & 27.8 \\
\hline 8 & высокоинтенсивные & 22 & 13.4 & 63.6 & 50.2 & 24.73 & 52 & 12.0 & 27.0 & 15.0 & 18.66 & 27.0 \\
\hline 9 & супернапряженные & 14 & 22.8 & 41.6 & 18.8 & 31.36 & 329 & 20.0 & 25.2 & 5.2 & 22.53 & 35.9 \\
\hline 10 & начало ослабления & 21 & 19.0 & 64.0 & 45.0 & 32.99 & 100 & 17.2 & 26.8 & 9.6 & 21.81 & 28.0 \\
\hline 11 & сопротивляющиеся & 20 & 14.8 & 60.6 & 45.8 & 31.82 & 69 & 13.0 & 26.5 & 13.5 & 19.63 & 26.6 \\
\hline 12 & слабеющие & 10 & 14.8 & 38.6 & 23.8 & 26.29 & 387 & 12.4 & 23.5 & 11.1 & 18.30 & 44.2 \\
\hline 13 & слабоватые & 28 & 18.0 & 56.6 & 38.6 & 42.08 & 553 & 13.8 & 26.0 & 12.2 & 22.33 & 44.6 \\
\hline 14 & слабые деревья & 9 & 16.4 & 61.2 & 44.8 & 39.18 & 2500 & 12.6 & 26.0 & 13.4 & 19.78 & 198.2 \\
\hline 15 & очень слабые & 4 & 19.8 & 62.8 & 43.0 & 48.60 & 2185 & 13.0 & 24.6 & 11.6 & 21.15 & 178.7 \\
\hline 16 & аутсайдеры & 5 & 31.6 & 66.8 & 35.2 & 46.22 & 63 & 15.4 & 21.9 & 6.5 & 18.56 & 21.4 \\
\hline 17 & усохшие сосны & 16 & 7.2 & 53.8 & 46.6 & 29.93 & 73 & 10.5 & 28.5 & 18.0 & 20.25 & 28.6 \\
\hline
\end{tabular}

Примечание. *Оптимумы по формулам [1] дендрорядов с учетом погрешности измерений. 
Bсе 11 показателей из таблицы 1 имеют волновые функции, которые мы называем асимметричными вейвлет-сигналами [3]. При этом они есть, но мы не умеем пока расшифровать эти сигналы.

Вейвлет (всплеск) - это математическая функция. Английское слово «wavelet» означает в переводе «маленькая волна». Вейвлеты - это семейство функций, «волны, идущие друг за другом». Осью абсцисс может быть не только время (в нашем случае диаметр ствола косвенно отображает возраст дерева), но и любая другая физическая величина. Вейвлет имеет четкую амплитудночастотную характеристику (АЧХ) и поэтому может изучаться методами классической механики колебаний [3].

При этом любой гармоничный вейвлет асимметричной формы имеет вид

$$
\begin{gathered}
y=\sum_{i=1}^{m} y_{i}, \\
y_{i}=A_{i} \cos \left(\pi x / p_{i}-a_{8 i}\right), A_{i}=a_{1 i} x^{a_{2 i}} \exp \left(-a_{3 i} x^{a_{4 i}}\right), p_{i}=a_{5 i}+a_{6 i} x^{a_{7 i}},
\end{gathered}
$$

где $y$ - показатель, $i$ - номер составляющей показателя, $m$ - количество членов модели (1), $x$ - объясняющая переменная (влияющий фактор), $A$ - амплитуда (половина) вейвлета (ось $y$ ), $p$ - полупериод колебания (ось $x$ ), $a_{1} \ldots a_{8}$ - параметры модели (1), принимающие числовые значения в процессе идентификации (1) по исходным данным в программной среде типа CurveExpert.

Физико-математический подход предполагает понимание рядов распределений таблицы 1 как отражений составного процесса поведения сосняка.

Сигнал - это материальный носитель информации. А информация нами понимается как мера взаимодействия [3].

Сигнал может генерироваться, но его приём не обязателен. Сосняк как вид древостоя известен несколько тысяч лет, но суть его как множества сигналов до сих пор не раскрыта.

Получается в лесной науке так, что изменение множества неизвестных сигналов лесоводам понятно на общем интуитивном (эвристическом) уровне. Но глубокое содержательное понимание ситуации сосняка (в момент рубки его модельных деревьев) приходит только в ходе выявления биотехнических волновых закономерностей [1-10].

Численность дендрорядов сосен. Количество сосен в дендрометрических рядах (рис. 1) сосняка изменяется в зависимости от ранга его дендроряда по четырехчленной формуле

$$
\begin{gathered}
N=N_{1}+N_{2}+N_{3}+N_{4}, \\
N_{1}=5,87121 \exp (-0,57516 p), N_{2}=0,62629 p^{2,08249} \exp \left(-0,031645 p^{1,64848}\right), \\
N_{3}=A_{3} \cos \left(\pi p / p_{3}+0,46730\right), A_{3}=-0,10819 p^{2,29939} \exp \left(-0,10524 p^{1,06386}\right), \\
\left.p_{3}=1,07739+0,00033637 p^{2,33688}\right), N_{4}=A_{4} \cos \left(\pi p / p_{4}-2,73999\right), \\
\left.A_{4}=308105,66 p^{3,71710} \exp \left(-12,52069 p^{0,20854}\right), p_{4}=0,67843+0,059661 p^{0,98466}\right) .
\end{gathered}
$$

Первые два члена уравнения (1) являются детерминированными, у которых полупериоды бесконечны. Физически они являются длинными колебаниями, полупериод их во много раз превышает интервал $p$ на оси абсцисс. 


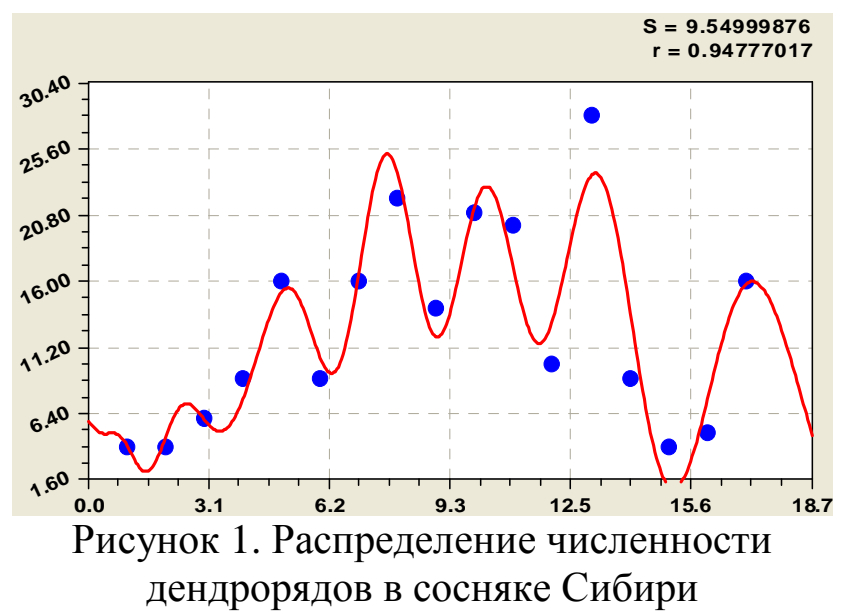

С повышением ранга дендроряда полупериод колебательного возмущения возрастает и ряды с высоким рангом, или с худшими условиями произрастания, как бы успокаиваются (или слабеют по уровню жизненной энергии), а амплитуда при этом у дендрометрических рядов 14-16 резко снижается. Таким образом, волны являются средством адаптации к внешним воздействиям.

По остаткам от модели (1) были получены (рис. 2) еще два вейвлета:

$$
N_{5}=A_{5} \cos \left(\pi p / p_{5}-2,94191\right),
$$

$$
\begin{gathered}
A_{5}=-22,54027 p^{4,14436} \exp \left(-4,66517 p^{0,42871}\right), p_{5}=1,95179+0,020641 p^{1,49398} ; \\
N_{6}=A_{6} \cos \left(\pi p / p_{6}-4,29568\right),
\end{gathered}
$$

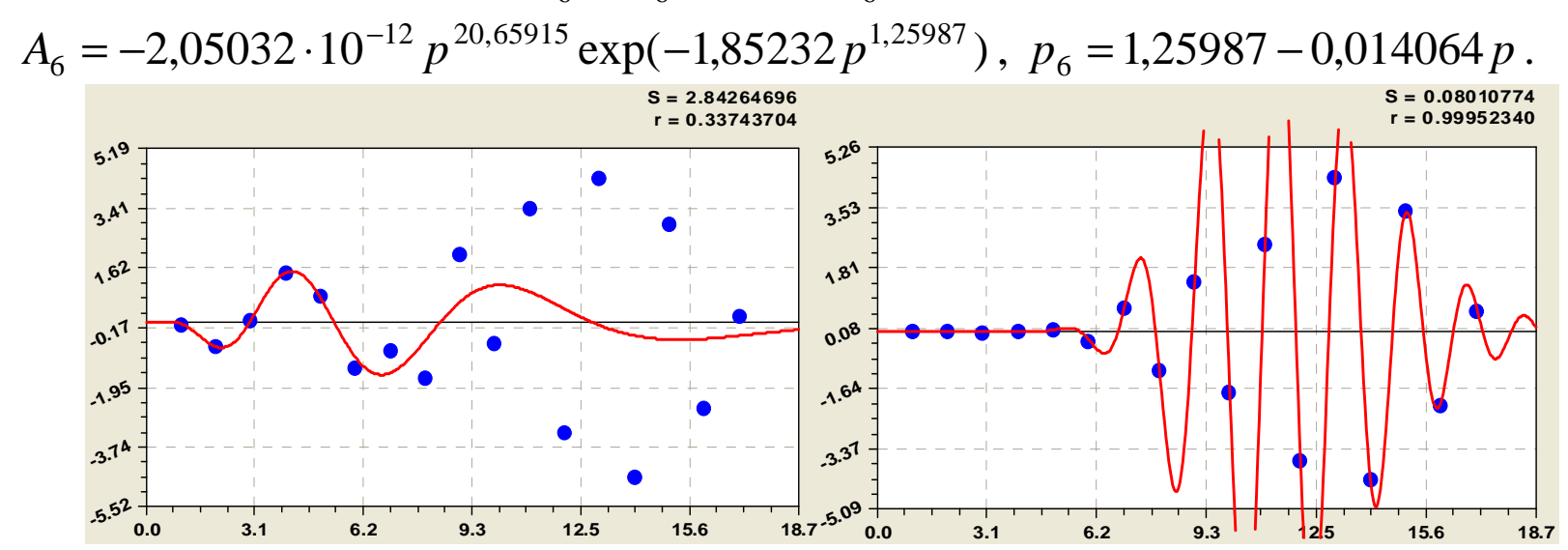

Рисунок 2. Дополнительные вейвлеты рангового распределения численности дендрорядов

Остатки (абсолютная погрешность) намного стали меньше погрешности измерения числа деревьев $\pm 0,5$ шт. Поэтому идентификацию прекращаем.

Параметры толщины ствола сосен. Каждый из пяти показателей толщины изменяется множеством вейвлетов, что позволяет давать объяснение поведению минимальных $D_{\min }$ и максимальных $D_{\max }$ диаметров в дендроряде сосен, а также размаху $\Delta D=D_{\max }-D_{\min }$, среднему статистическому $\bar{D}$ (не среднеарифметическому) и оптимуму $H^{*}=f\left(D^{*}\right)$ толщины ствола сосен.

Из-за малого объема статьи в таблице 2 даны составляющие только основной закономерности.

По остаткам от основных биотехнических закономерностей дополнительно были получены до 8-10 вейвлетов. Это указывает, что развитие в ширину и рост в высоту разновозрастных сосен происходит по множеству колебательных возмущений. Нужно только в содержательном смысле научиться расшифровывать эти вейвлет-сигналы.

C наибольшей адекватностью 0,9997 (табл. 2) график на рисунке 3 относится к распределению оптимального диаметра $D^{*}$ по рангам 18 у дендрорядов ангарских сосен. 
Таблица 2

Параметры волнового уравнения (1) распределения 18 дендрорядов по параметрам толщины ствола 219 ангарских сосен, см

\begin{tabular}{|c|c|c|c|c|c|c|c|c|c|}
\hline \multirow{2}{*}{$\begin{array}{c}\text { № } \\
i \\
\end{array}$} & \multicolumn{4}{|c|}{ Амплитуда колебания } & \multicolumn{4}{|c|}{ Полупериод и сдвиг колебания } & \multirow{2}{*}{$\begin{array}{l}\text { Коэфф } \\
\text { коррел }\end{array}$} \\
\hline & $a_{1 i}$ & $a_{2 i}$ & $a_{3 i}$ & $a_{4 i}$ & $a_{5 i}$ & $a_{6 i}$ & $a_{7 i}$ & $a_{8 i}$ & \\
\hline \multicolumn{10}{|c|}{ Минимальный диаметр $D_{\min }$ сосен в дендрорядах } \\
\hline 1 & 22,28248 & 0 & 0,023669 & 1 & 0 & 0 & 0 & 0 & \multirow{3}{*}{0,9623} \\
\hline 2 & 3,33113 & 2,95520 & 0,80238 & 0,94485 & 5,05309 & $-0,35033$ & 0,97260 & 0,67586 & \\
\hline 3 & $-6,47508 \mathrm{e}-18$ & 15,28636 & 0 & 0 & 2,11637 & 0 & 0 & $-4,79970$ & \\
\hline \multicolumn{10}{|c|}{ Максимальный диаметр $D_{\max }$ сосен в дендрорядах } \\
\hline 1 & 61,68550 & 0 & 0,0011070 & 0 & 0 & 0 & 0 & 0 & \multirow{4}{*}{0,9709} \\
\hline 2 & $-147,42788$ & 2,40149 & 3,19820 & 0,42889 & 2,88288 & 0,29669 & 0,58808 & 1,79578 & \\
\hline 3 & $-9,46471 e-19$ & 40,09367 & 6,85871 & 0,84009 & 0,51304 & 0,00068849 & 2,26894 & 3,05594 & \\
\hline 4 & $-46,65305$ & 2,08319 & 1,14540 & 1 & 0,75877 & 0,074361 & 1 & 2,49278 & \\
\hline \multicolumn{10}{|c|}{ Размах диаметра $\Delta D=D_{\max }-D_{\min }$ сосен в дендрорядах } \\
\hline 1 & 39,53972 & 0 & $-0,0025378$ & 1 & 0 & 0 & 0 & 0 & \multirow{3}{*}{0,9431} \\
\hline 2 & $-4,02141$ & 1,79141 & 0,38090 & 0,89130 & 1,54437 & $4,52070 \mathrm{e}-5$ & 2,53288 & $-0,59669$ & \\
\hline 3 & 10,99341 & 0,51141 & 0,028338 & 1,69818 & 3,77415 & 0,00033894 & 3,49261 & 4,28142 & \\
\hline \multicolumn{10}{|c|}{ Средний арифметический диаметр $\bar{D}$ ствола сосен дендрорядов } \\
\hline 1 & 39,50274 & 0 & 0,025569 & 1 & 0 & 0 & 0 & 0 & \multirow{3}{*}{0,9476} \\
\hline 2 & $-1,91070 \mathrm{e}-8$ & 7,75499 & 6,46869 & 3,06336 & 0 & 0 & 0 & 0 & \\
\hline 3 & 3,01486 & 1,12526 & 0,18835 & 1 & 10,75009 & $-4,81139$ & 0,21824 & $-0,94643$ & \\
\hline \multicolumn{10}{|c|}{ Оптимальный диаметр $D^{*}$ по расчетной модели каждого дендроряда } \\
\hline 1 & 123,1731 & 0 & 0,14107 & 1 & 0 & 0 & 0 & 0 & \multirow{4}{*}{0,9997} \\
\hline 2 & $1,65110 \mathrm{e}-127$ & 164,83713 & 5,91547 & 1,18622 & 0 & 0 & 0 & 0 & \\
\hline 3 & $-0,21651$ & 4,76828 & 1,05024 & 0,58024 & 0,34929 & 0,032263 & 0,95241 & 0,12220 & \\
\hline 4 & $8,62421 \mathrm{e}-11$ & 23,70959 & 2,62910 & 1 & 12,07770 & $-2,20125$ & 0,41909 & $-1,60919$ & \\
\hline
\end{tabular}

Заметно, что слабеющие сосны вдруг начинают показывать свое стремление к высоким значениям толщины ствола - вплоть до диаметра 25 м.
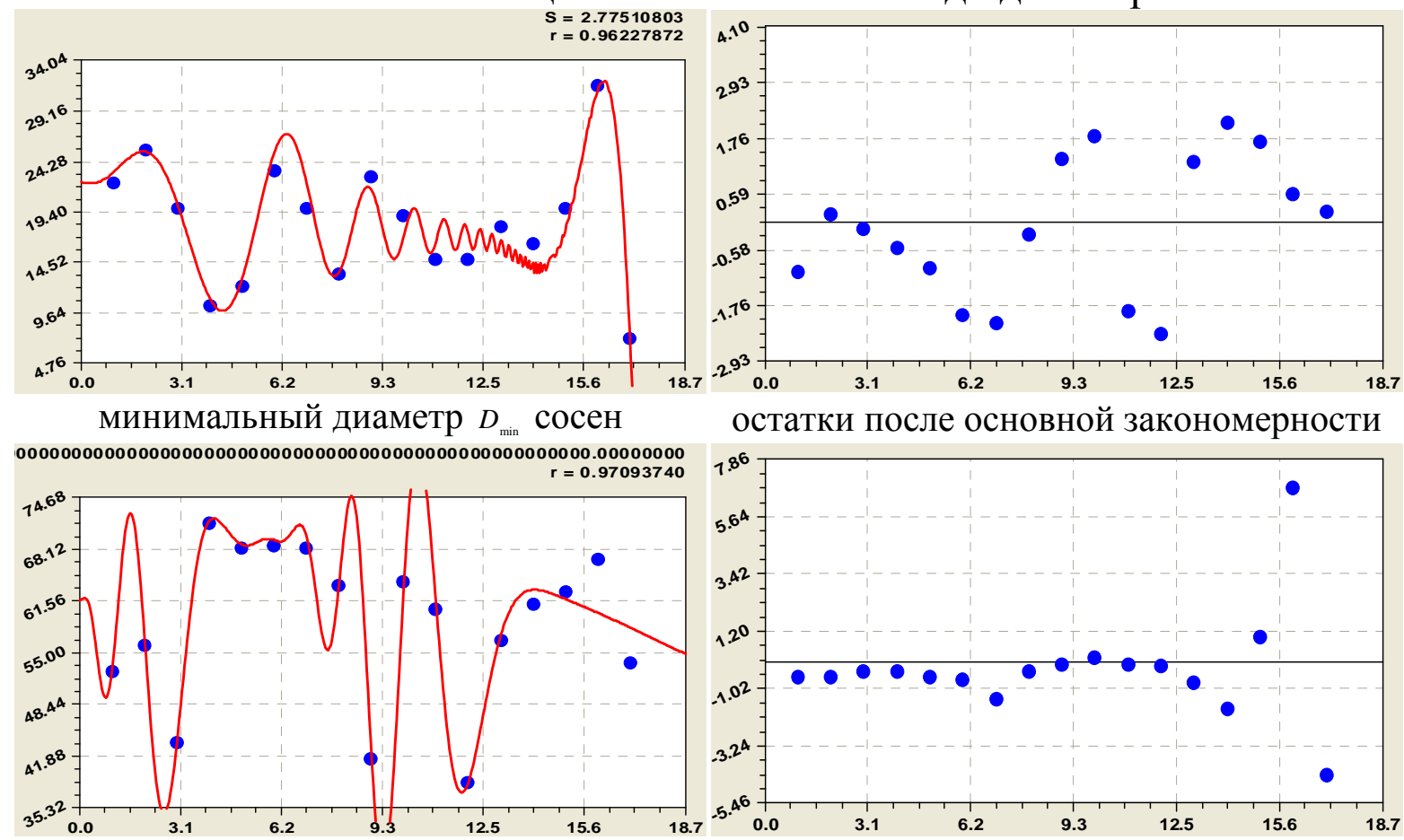

остатки после основной закономерности

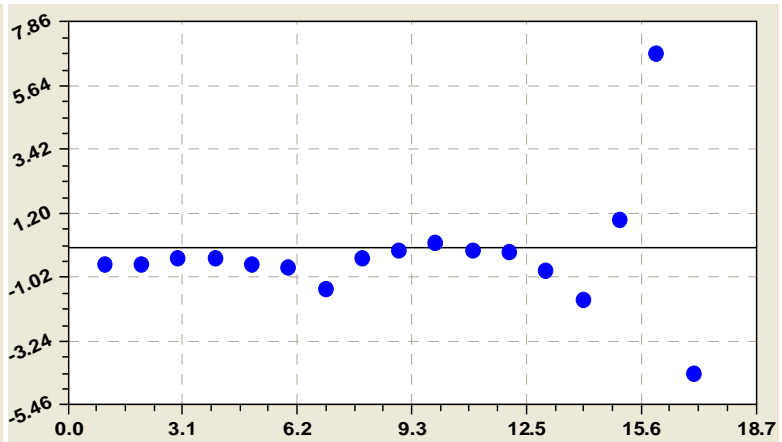

максимальный диаметр $D_{\max }$

остатки после основной закономерности 

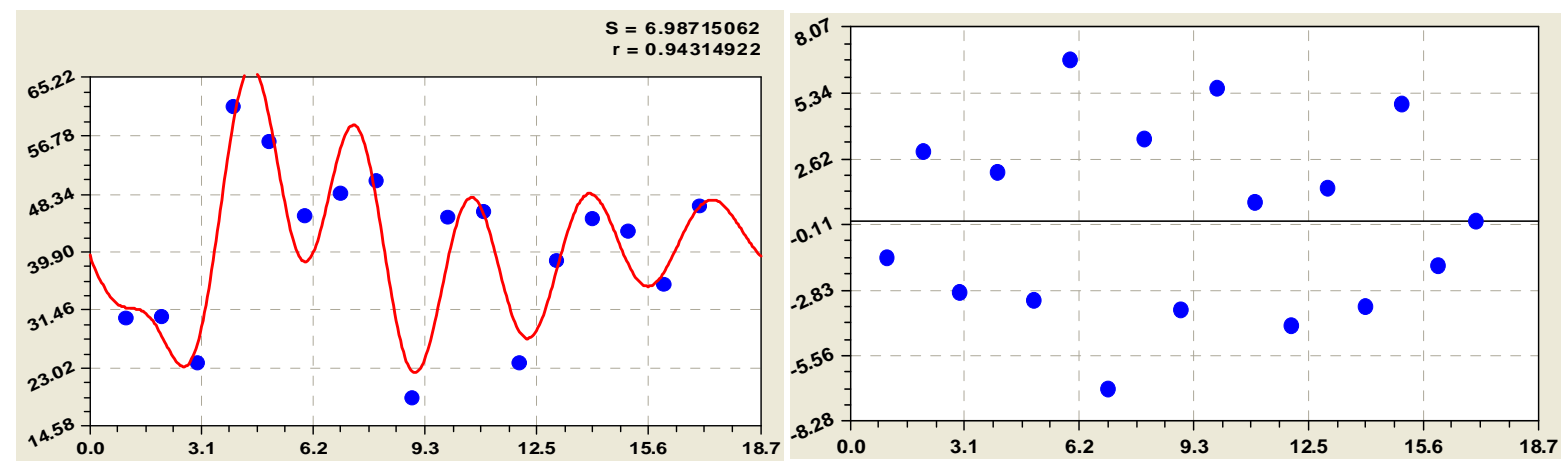

размах диаметра $\Delta D=D_{\max }-D_{\min } \operatorname{coceH}$

остатки после основной закономерности
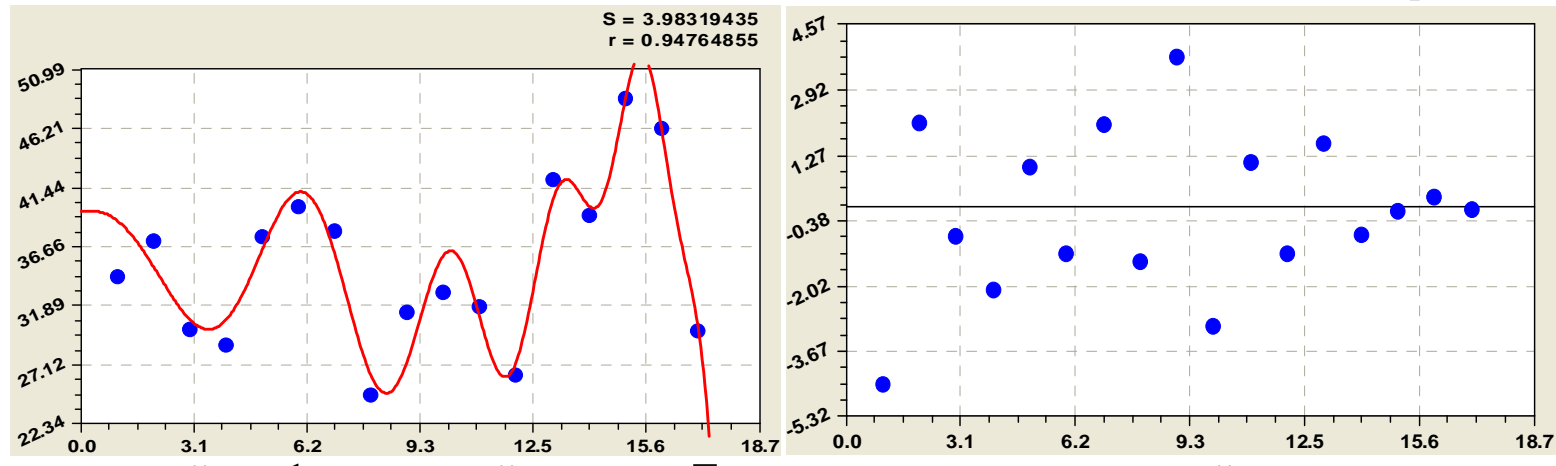

средний арифметический диаметр $\bar{D}$

остатки после основной закономерности
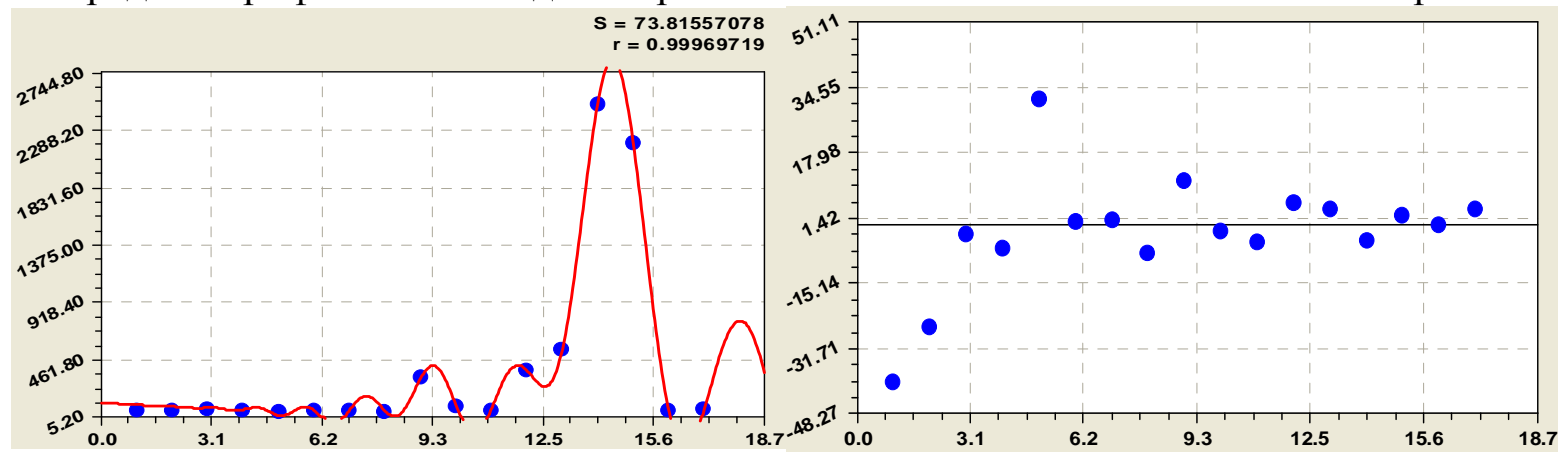

оптимальный диаметр $D *$ дендроряда остатки после основной закономерности

Рисунок 3. Основные закономерности рангового распределения показателей толщины ствола сосен

Но импульсивное стремление расти в толщину чаще всего не обеспечено условиями среды, и этому развитию мешают соседние деревья своими стволами и кронами. По этим пяти параметрам толщины ствола можно выявить в дальнейшм закономерности влияния диаметра кроны модельных сосен.

Параметры высоты ствола сосен. Аналогично толщине рассматриваются пять разных показателей высоты ствола (табл. 3 и рис. 4).

Слабеющие сосны 14-15 дендрорядов «имеют желание» не только утолщаться, но и расти в высоту вплоть до теоретического предела в $200 \mathrm{м.}$

Причем закономерности типа $H=f(D)$ кривых высот у всех 18 дендрорядов [1] дают наибольшую адекватность моделирования.

В таблице 4 дано сравнение выявленных формул по уровню корреляции и числу параметров, содержащихся в статистической модели.

Лучшим показателем становится максимальная высота ствола.

Она имеет шестое место по коэффициенту корреляции, но первые места по количеству членов математической модели и количеству её параметров. 
Таблица 3

Параметры волнового уравнения (1) распределения 18 дендрорядов по параметрам высоты ствола 219 ангарских сосен, м

\begin{tabular}{|c|c|c|c|c|c|c|c|c|c|}
\hline \multirow{2}{*}{$\begin{array}{c}\text { № } \\
i \\
\end{array}$} & \multicolumn{4}{|c|}{ Амплитуда колебания } & \multicolumn{4}{|c|}{ Полупериод и сдвиг колебания } & \multirow{2}{*}{$\begin{array}{l}\text { Коэфф } \\
\text { коррел }\end{array}$} \\
\hline & $a_{1 i}$ & $a_{2 i}$ & $a_{3 i}$ & $a_{4 i}$ & $a_{5 i}$ & $a_{6 i}$ & $a_{7 i}$ & $a_{8 i}$ & \\
\hline \multicolumn{10}{|c|}{ Минимальная высота $H_{\min }$ ствола сосен в дендрорядах } \\
\hline 1 & 27,47674 & 0 & 0,21215 & 0,46498 & 0 & 0 & 0 & 0 & \multirow{3}{*}{0,9965} \\
\hline 2 & 191,09825 & 4,40686 & 5,14532 & 0,43166 & 3,75340 & $-0,23153$ & 0,87722 & $-4,65422$ & \\
\hline 3 & $-0,0034393$ & 5,67318 & 0,78279 & 0,91456 & 4,51928 & $-0,00014628$ & 3,06855 & 3,30077 & \\
\hline \multicolumn{10}{|c|}{ Максимальная высота $H_{\max }$ ствола сосен в дендрорядах } \\
\hline 1 & 32,52538 & 0 & 0,061791 & 0,54004 & 0 & 0 & 0 & 0 & \multirow{2}{*}{0,9706} \\
\hline 2 & 0,00057489 & 3,13686 & 0 & 0 & 0,43404 & 0,61691 & 0,20058 & 4,25453 & \\
\hline \multicolumn{10}{|c|}{ Размах высоты ствола $\Delta H=H_{\max }-H_{\min }$ сосен в дендрорядах } \\
\hline 1 & 5,82606 & 0 & $-0,29506$ & 0,35003 & 0 & 0 & 0 & 0 & \multirow{3}{*}{0,9770} \\
\hline 2 & $-1,02177$ & 3,82399 & 0,78179 & 1 & 4,67313 & $-0,29603$ & 1 & 1,11583 & \\
\hline 3 & 7,63309E-18 & 17,27031 & 0,49259 & 0,93446 & 1,87187 & 0 & 0 & 4,56326 & \\
\hline \multicolumn{10}{|c|}{ Средняя арифметическая высота $\bar{H}$ ствола сосен дендрорядов } \\
\hline 1 & 29,64882 & 0 & 0,12236 & 0,43905 & 0 & 0 & 0 & 0 & \multirow{2}{*}{0,9701} \\
\hline 2 & 4,73057 & 2,46839 & 1,76026 & 0,56341 & 2,30096 & $-0,0015754$ & 2,16399 & 2,56782 & \\
\hline \multicolumn{10}{|c|}{ Оптимальная (предельная) высота $H^{*}$ ствола по расчетной модели каждого дендроряда } \\
\hline 1 & 32,09858 & 0 & $3,14642 \mathrm{e}-5$ & 3,81929 & 0 & \begin{tabular}{|l|}
0 \\
\end{tabular} & 0 & \begin{tabular}{|l}
0 \\
\end{tabular} & \multirow{3}{*}{0,9978} \\
\hline 2 & $3,49885 \mathrm{e}-150$ & 187,6328 & 5,50770 & 1,24170 & 0 & 0 & 0 & 0 & \\
\hline 3 & $4,38396 \mathrm{e}-15$ & 23,89888 & 2,77238 & 0,85502 & 0,77877 & 0,23325 & 0,27611 & 4,57679 & \\
\hline
\end{tabular}

Таблица 4

Сравнение ранговых распределений дендрорядов

\begin{tabular}{|c|c|c|c|c|c|c|c|}
\hline \multicolumn{3}{|c|}{ Толщина ствола сосен } & \multicolumn{4}{|c|}{ Высота ствола сосен } \\
\hline $\begin{array}{c}\text { Пока- } \\
\text { затель }\end{array}$ & $\begin{array}{c}\text { Коэф. } \\
\text { корр. }\end{array}$ & $\begin{array}{c}\text { Кол-во } \\
\text { членов }\end{array}$ & $\begin{array}{c}\text { Кол-во } \\
\text { парам. }\end{array}$ & $\begin{array}{c}\text { Пока- } \\
\text { 3атель }\end{array}$ & $\begin{array}{c}\text { Коэф. } \\
\text { корр. }\end{array}$ & $\begin{array}{c}\text { Кол-во } \\
\text { членов }\end{array}$ & $\begin{array}{c}\text { Кол-во } \\
\text { парам. }\end{array}$ \\
\hline$D_{\min }$ & 0,9623 & 3 & 14 & $H_{\min }$ & 0,9965 & 3 & 19 \\
\hline$D_{\max }$ & 0,9709 & 4 & 25 & $H_{\max }$ & 0,9706 & $\mathbf{2}$ & $\mathbf{9}$ \\
\hline$\Delta D$ & 0,9431 & 3 & 18 & $\Delta H$ & 0,9770 & 3 & 15 \\
\hline $\bar{D}$ & 0,9476 & 3 & 13 & $\bar{H}$ & 0,9701 & 2 & 11 \\
\hline$D^{*}$ & $\mathbf{0 , 9 9 9 7}$ & 4 & 21 & $H^{*}$ & 0,9978 & 3 & 15 \\
\hline
\end{tabular}

Таким образом, английская система дендрометрии $[11,12]$ по высотам у 100 лидирующих деревьев оказалась доказанной не только зарубежными исследованиями. Она доказана и по результатам моделирования 10 показателей толщины и высоты ствола у 219 ангарских сосен по 18 дендрометрическим рядам.

Принятая в нашей стране система «средних арифметических деревьев» по данным таблицы 4 оказалась хуже (11 параметров модели по средней высоте и 13 по среднему диаметру).

Выводы. Анализ выявленных биотехнических закономерностей рангового распределения показателей сосняка по пяти их различиям граничных условий и экстремумов позволяет научно обосновать мероприятия в проекте лесной аренды [4], изучать динамику территориального лесопользования при сравнении со странами мира [5], а также создавать функциональную структуру электронной тематической лесной карты [10] и в дальнейшем географическую информационную систему на основе тематических лесных карт. 

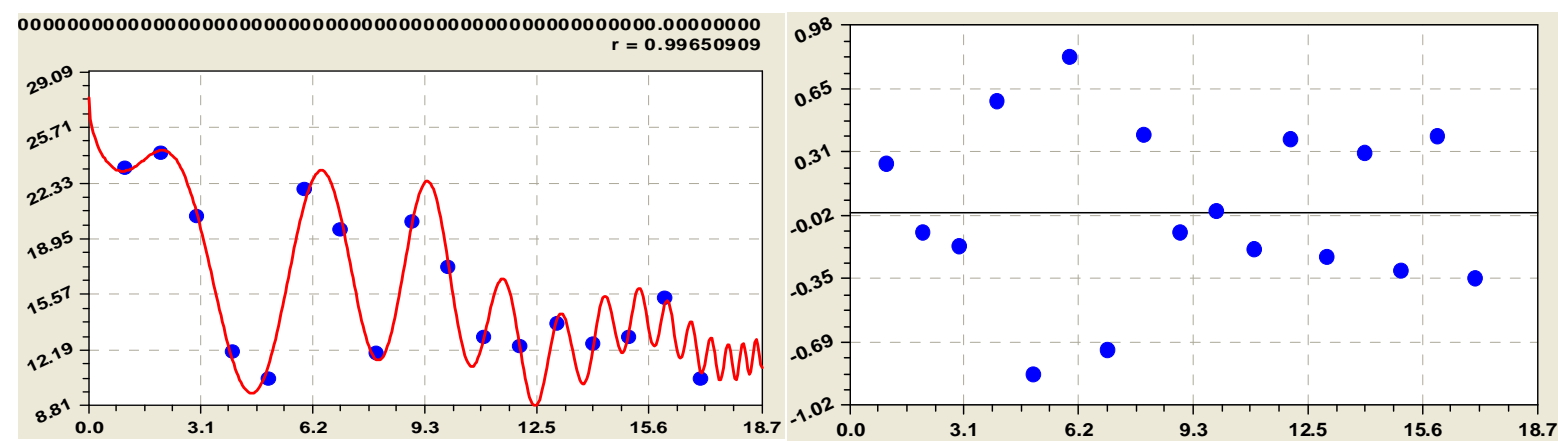

минимальная высота $H_{\text {min }}$

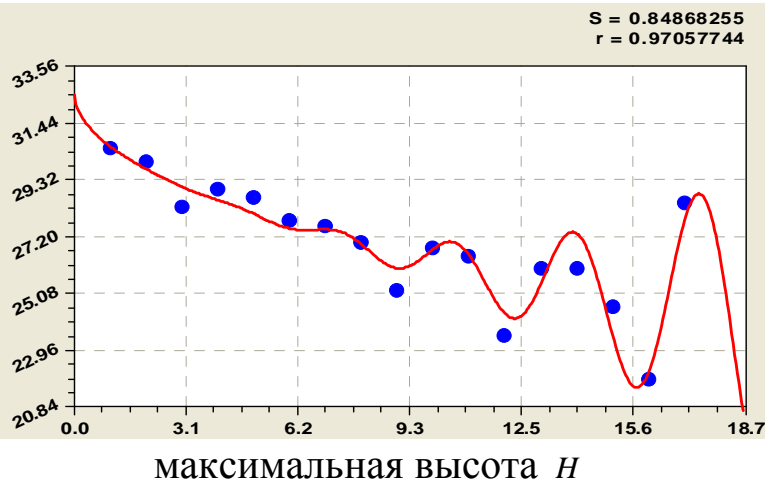

остатки после основной закономерности
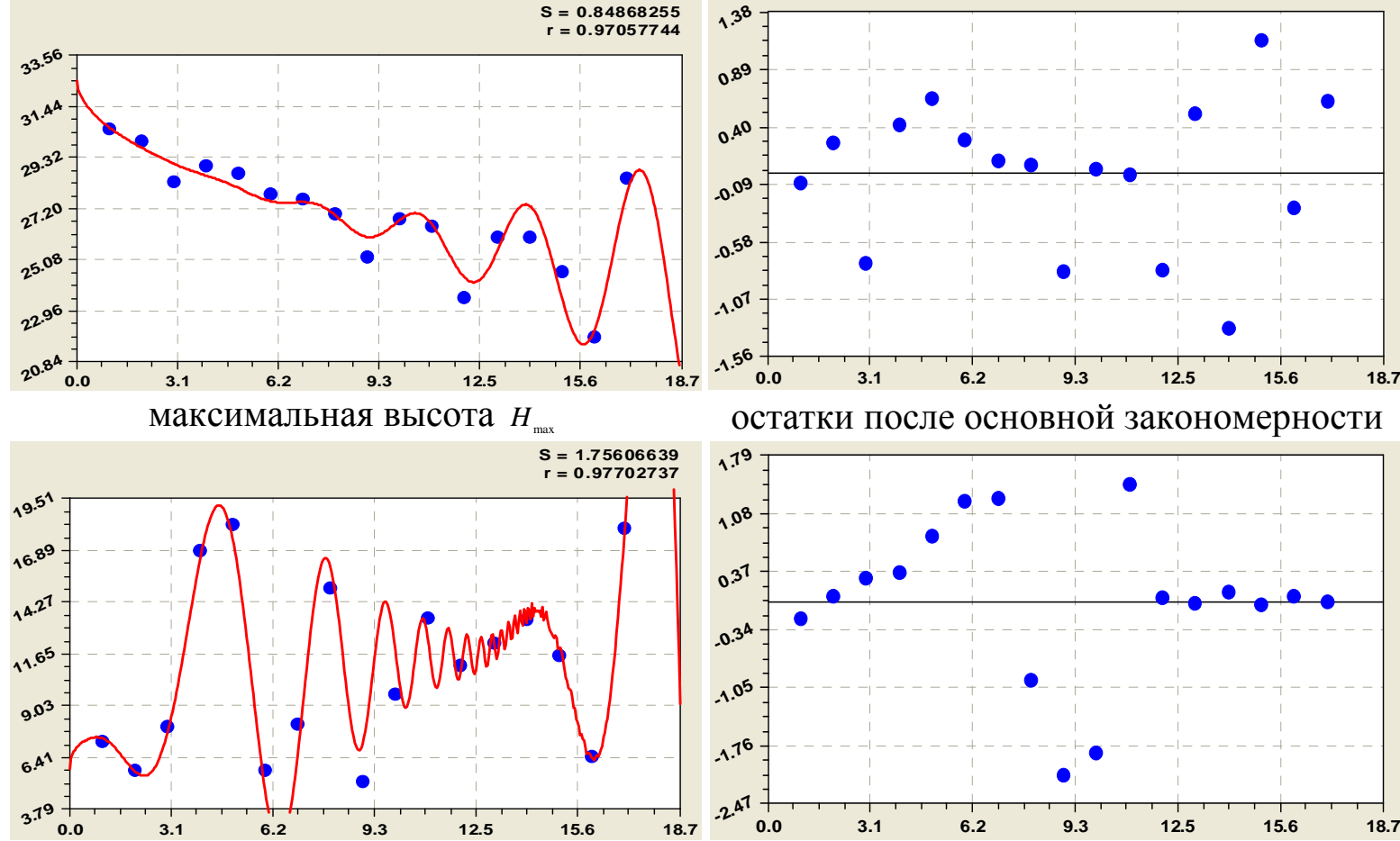

остатки после основной закономерности

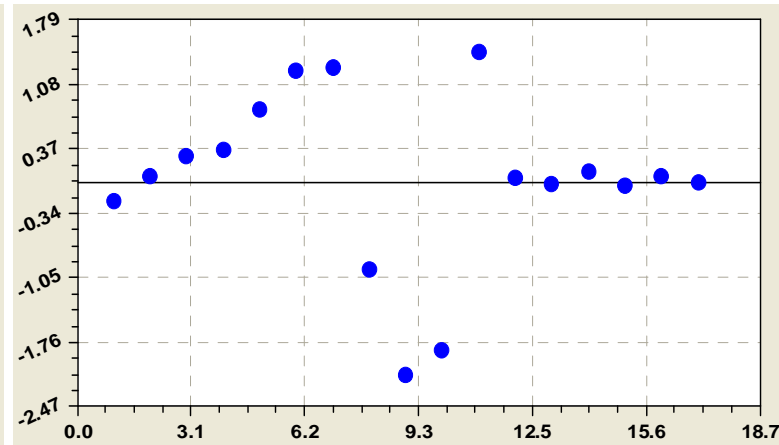

размах высоты ствола $\Delta H=H_{\max }-H_{\text {min }}$

остатки после основной закономерности
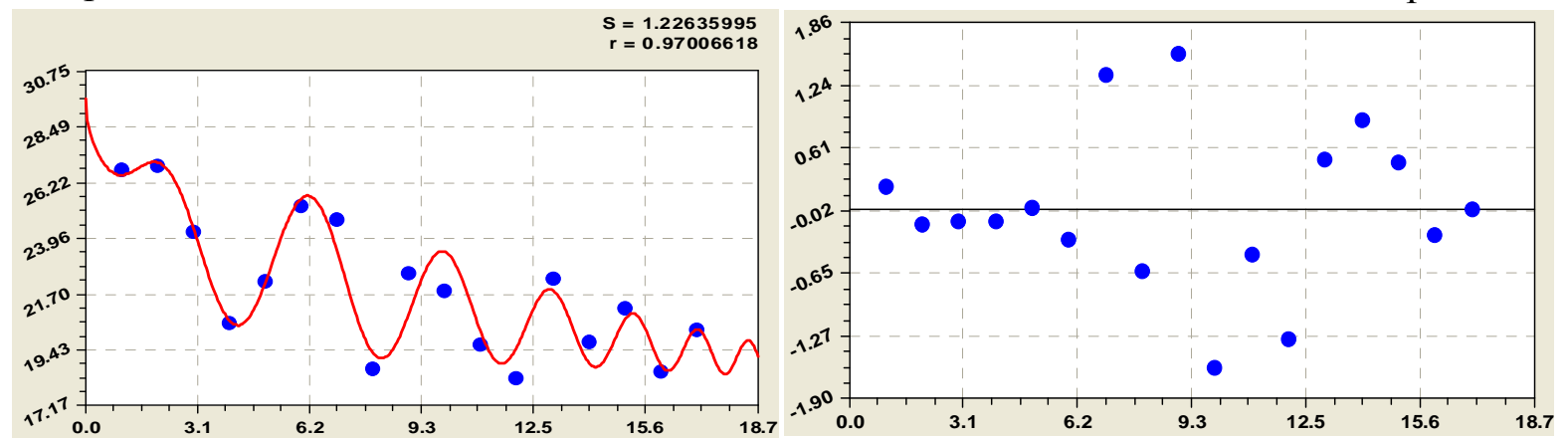

средняя арифметическая высота $\bar{H}$
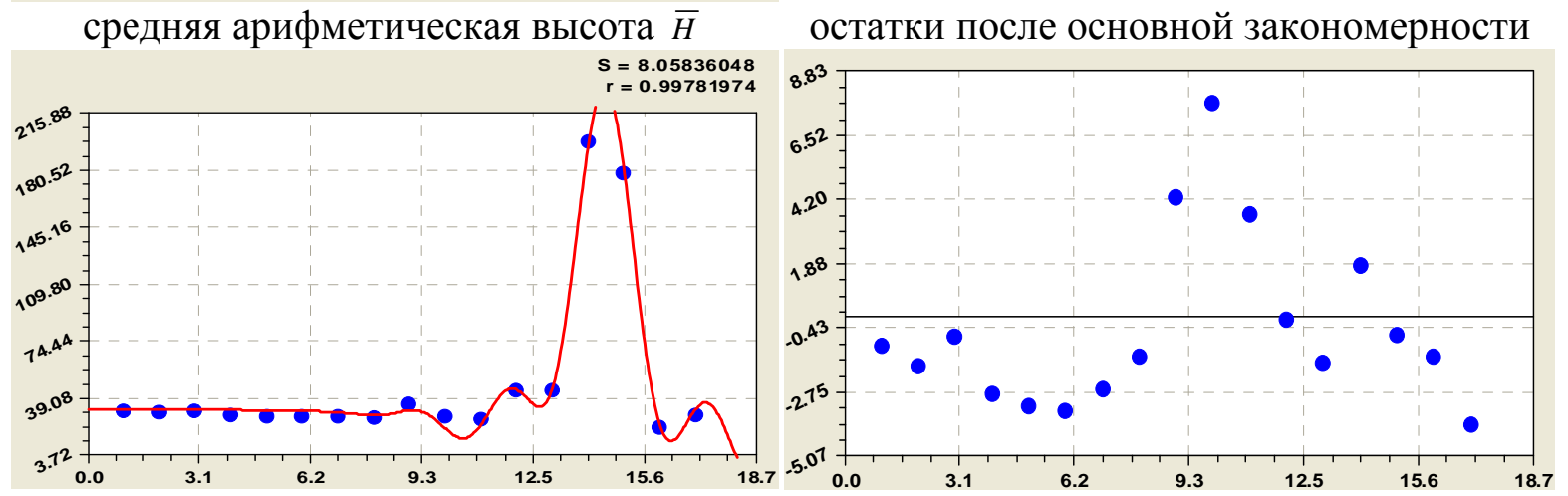

оптимальная (предельная) высота $H^{*}$ остатки после основной закономерности

Рис. 4. Основные закономерности рангового распределения показателей высоты ствола сосен 


\section{СПИСОК ЛИТЕРАТУРЫ}

1. Мазуркин П.М. Дендроряды разновозрастного сосняка по кривым высот // Междисциплинарные исследования в области математического моделирования и информатики / Материалы 4-й научно-практ. internet-конф. Отв. ред. Ю.С. Нагорнов. Ульяновск: Изд-во SIMJET, 2014. С. 122-130.

2. Мазуркин П.М. Биотехнические закономерности таксационных показателей пробных площадей // Матер. междунар. конф. «Международное сотрудничество в лесном секторе: баланс образования, науки и производства» (3-5 июня 2009). Йошкар-Ола: МарГТУ, 2009. С. 84-87.

3. Мазуркин П.М. Вейвлет-анализ ряда простых чисел // Фундаментальные исследования. 2011. № 12. С.568-575.

4. Мазуркин П.М. Лесная аренда и рациональное лесопользование. Йошкар-Ола: МарГТУ, 2007. 524 с.

5. Мазуркин П.М. Лесоаграрная Россия и мировая динамика лесопользования. Йошкар-Ола: МарГТУ, 2007. 334 с.

6. Мазуркин П.М. Принцип экосистемной суперпозиции: группировки диаметра ствола модельных сосен из лесных культур Волго-Вятского региона // Леса России в XXI веке: материалы шестой междунар. науч.-техн. интернетконф., март 2011. СПб.: ЛТА, 2011. С. 121-136.

7. Мазуркин П.М. Распределение фитомассы сосняка по пробным площадям // Леса России и хозяйство в них. 2009. № 3. С.22-31.

8. Мазуркин П. М., Михайлова С.И. Комплексные исследования фитомассы лесолугового фитоценоза в Республике Марий Эл // Сб. статей III Междунар. научно-практ. конф. Саратов: СарГАУ, 2011. С. 22-26.

9. Мазуркин П.М., Михайлова С.И. Распределение растительной массы в лесолуговом фитоценозе // Вестник УМО по образованию в области природообустройста и водопользоваия. 2011. № 3. С. 330-340.

10. Русинова Н.В., Мазуркин П.М., Фадеев А.Н. Методика построения электронной тематической лесной карты // Современные наукоёмкие технологии. №1. 2012. С.35-41.

11. Питер Х. Пирс. Введение в лесную экономику / Пер. с англ.: Учебн. пос. М.: Экология, 1992. 224 с.

12. Хендерсон-Ховат Д.Б. Регулирование и прогнозирование объемов производства древесины // Интегрированное управление лесами при многоцелевом использовании их в условиях рыночной экономики. Матер. конфер. междунар. союза ИЮФРО. М.: ВНИИЛМ. 1993. С. 233-242.

\section{STRUCTURAL AND FUNCTIONAL CHARACTERISTICS DENDRITIC SERIES UNEVEN-AGED PINE FORESTS OF SIBERIA ON A CURVE HEIGHTS}

(C) 2015

P.M. Mazurkin, Doctor of Technical Sciences, Professor, Academician of the Russian Academy of Natural Sciences and the Russian Academy of Natural Sciences, Member of the European Academy of Natural Sciences,

Volga State Technological University (Yoshkar-Ola), Russia, kaf_po@ mail.ru 